\title{
DEVELOPMENT OF DIGITAL MONITORING METHODOLOGY
}

\author{
By: \\ Nahar Cahyandaru, S.Si \\ Brahmantara. ST
}

\begin{abstract}
Introduction
Monitoring is one of most important works in conservation after restoration of the cultural properties. Monitoring is conducted to understand the deteriorations and damages occurring in the monument. The monitoring data are also used as the basic information for conservation work. Generally the scientific monitoring parameters are microorganism, chemical, and physical deterioration.
\end{abstract}

\section{a. Microorganism Growth}

The types of microorganism growing on the cultural properties are moss, lichens, and algae. The growth of organism is influenced by the climate condition. As a country in tropical region, Indonesia has two seasons (rainy and dry season). In rainy season it grows become very quickly, and decreases in dry season. At the end of dry season the organism gets dry and dies.

The monitoring of micro organism is conducted in rainy season, while it grows the highest. In this condition the conservation works are cleaning by mechanical (manual) and water. The monitoring data are used for the conservation work to do the treatment with bio controlling chemicals. The chemicals are applied before the next rainy season to prevent the growth. According to the monitoring data, conservator applies the chemicals on the monument. Monitoring data are also used for the evaluation of the conservation effectiveness.

b. Chemical Deterioration

Chemical deteriorations are monitored in the stone monument, for example in Borobudur are efflorescent, salt deposit (scaling), cementation, postule, and alveoli. Efflorescence, scaling, and cementation are formed at the same process.

The monitoring data are used for conservation work for cleaning, both in chemical and mechanical. The location and population of the deteriorations found in the monitoring are used by conservator to conduct the cleaning. Monitoring of alveoli and postule are used by conservator to identify the location to be treated.

(* This article is a part of the paper "Monitoring of the Borobudur Post Restoration" presented at : 21st Conference on International Cooperation in Conservation in Tokyo, 3-8 December 2007).

The whole monitoring of chemical deteriorations are used to understand the process and minimize the population growth. These chemical deteriorations are still problems to be solved in Borobudur temple.

\section{c. Physical Deteriorations}

Monitoring of physical deteriorations consist of fissuring, erosion, and other physical damages. Monitoring data of fissuring are used by conservator to identify the location to be restored. The erosion and other physical damages are related to the chemical deteriorations. Monitoring of the physical deteriorations is used to understand the other damages. Fissuring data are used to control the stability of the building and stone formation. In the fissuring case, after joining the crack, the stability of stone formation is checked and stabilized by wedging.

The objective of the monitoring is to quantify the population of each deterioration parameter. The monitoring data are used as the basic guide of the conservation system, and to describe the deterioration factor and its process.

The common methodology of the monitoring is by mapping the whole relief. Each parameter is done at different time or scheduled with different map. The technical drawing are used as the basic map representing the formation of the stone blocks. The map is printed on the white paper and the result of the observation is written on it.

\section{Methodology}

The monitoring by mapping can describe the deterioration condition of the stone and is useful for conservation work. However, the percentage of the deterioration is difficult to be accurately quantified by mapping the direct observation. The percentage of deterioration area on the stone block is calculated by estimation of the observatory. The observation data are sufficient for the basic information for the conservation work only. The more exact quantify monitoring system is needed for the scientific evaluation of the deterioration change.

The new monitoring methodology develops by modifying the direct observation with digital drawing. This methodology is suggested by Mr. Costantino Meucci Expert from UNESCO since the last two years. The main objective of the UNESCO Expert mission is to understand well the deterioration phenomena of Borobudur especially in the rate of efflorescence and scaling. For this purpose we need precise and accurate data of the monitoring for all deterioration type. Because of the large area of the temple, this monitoring is done on 16 panels of relief as samples. These panels are observed every two month to monitor the deterioration change. 


\section{Monitoring}

The outline of the monitoring method is described as the following:

a. Taking photograph the panels

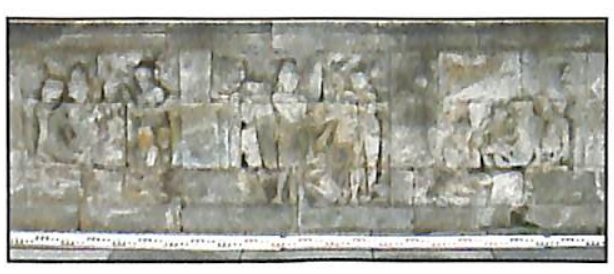

b. Importing the picture to AutoCAD program and fitting the dimension picture with the original

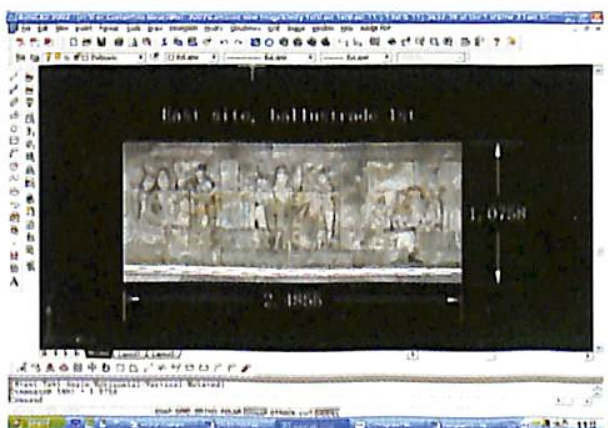

c. Field observation to compare the original and picture. Those photos are printed as needed to be used for survey related to the stone condition in the field, according to the parameter made. The result of the field survey is used for conducting photo digitalization that has been transferred to AutoCAD.

d. Digitalizing the area of each deterioration on AutoCAD. Digitalization is conducted by the personnel taking part in conducting the survey in the field to avoid the mistake in processing data. Digitalization lines are made in various colours to differentiate the parameter one to another, as the following:

$\begin{array}{ll}\text { I. Algae/moss } & \text { : green } \\ \text { ii. Alveoli } & \text { : magenta } \\ \text { iii. Efflorescence } & \text { : brown } \\ \text { iv. Salt deposit } & \text { : grey } \\ \text { v. Cementation } & \text { : yellow } \\ \text { vi. Ochre } & \text { : blue } \\ \text { vii. Scaling } & \text { : violet } \\ \text { viii. Laminar corrosion } & \text { : black } \\ \text { ix. Fissuring } & \text { : red } \\ \text { x. Restoration } & \text { : pink }\end{array}$

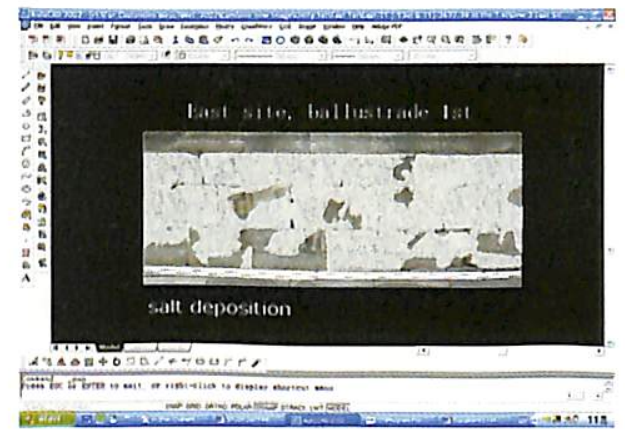

Other sample of the digitalization beside salt deposit above is ochre, as figured below.
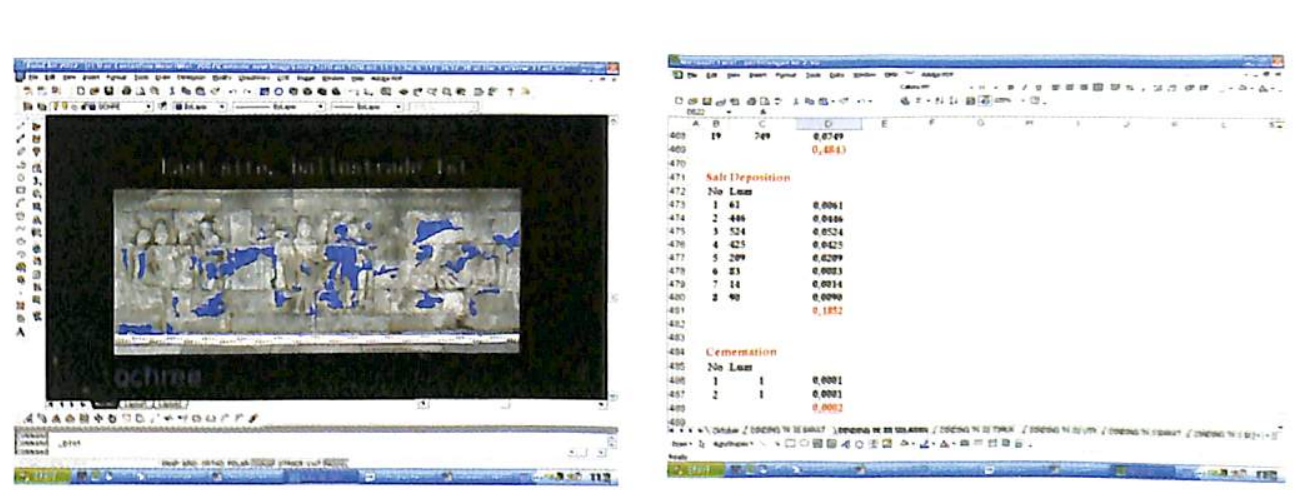

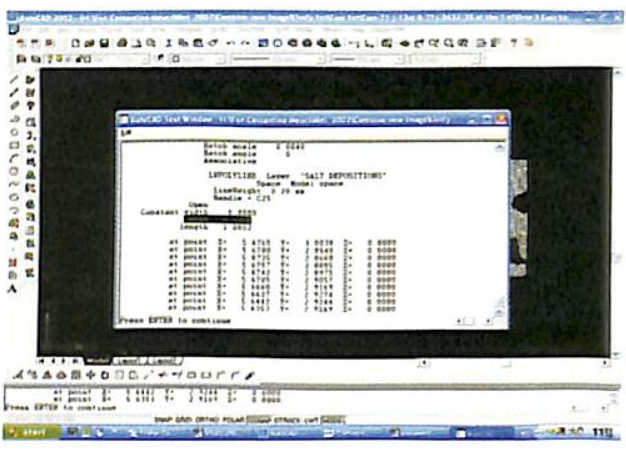

The volume of each parameter is automatically calculated by using AutoCAD menu then the result of the digitalization is used as the standard of comparison to the observation period, before and after.

f. Calculation of the deterioration area AutoCAD, the quantitative data can calculate on other program, such as Excel.
After quantifying the area on
e. Quantifying the area on AutoCAD

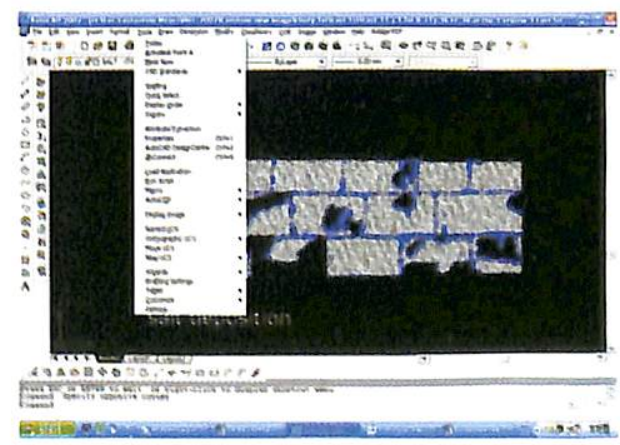




\section{Monitoring}

\section{Discussion}

The new developed monitoring methodology as described above gives the accurate and precise data of deteriorations and damages and better quantitative change to understand the deterioration process. The weaknesses of this methodology are it is taken in long enough time and needs good photograph instrument and the computer expert operator.

The monitoring problem of Borobudur temple is as large as the size of the building. The length of each side is 121 metre, and the height of the whole building 35.40 meter. The body of the temple consists four levels of main wall and five levels of balustrades with the sculpture gallery (bas-relief). Totally the number of panels of basrelief are 1460 panels. The deterioration monitoring is focussed on the main wall and balustrade with the bas-relief. Because of the large area of the temple, this monitoring is done on 16 panels of relief as samples. These panels are observed every two month to monitor the deterioration change.

The technical difficulties of this methodology are to get the photograph picture from the exact view of each monitoring period, and also the good picture without lens distortion. The photographer has to take the picture form the same distance and angle. To get the good picture without lens distortion the photographer must use the suitable instrument quality.

\section{Conclusion}

Monitoring is one of the most important activities in conservation after the cultural properties restored. The monitoring is useful to control and maintain the restoration system works. And also to understand the whole deterioration and damages that still happen on cultural properties, in order to control its rate. The monitoring data are also directly used by conservation worker to identify the location to be conducted the intervention.

The new monitoring methodology developed by digitalization is very useful to get the quantitative data of the deterioration and damages. Good photograph instrument, computer operator and photographer expert are needed to get the best system of the monitoring. .

\section{References}

Cahyandaru, Kasivati, Sulihanto, (2007), Evaluation of Monitoring and Repairing Borobudur Temple Related to the Stone Degradation by Seepage Water, Borobudur Heritage Conservation Office

Kumar \& Kumar, (1999), Biodeterioration of Stone in Trapical Environtment, the Getty Conservation Institute, USA

Meucci. C, (2007), Degradation and Conservation of the Stone, Candi Borobudur Research Program, Rome

Monitoring Team of BHCI (20r 2007), Monitoring of Deteriora on Borobudur Panels Sample. Traditional Mortar Application, Bimonthly Report from Borobudur Heritage Conservation Office to UNESCO

Parkani, (1999), Archaeological Chemistry, Bradshaw \& Co, London

Price. C A, (1996), Stone Conservation; an Overvien of Current Research, the Getty Conservation Institute, USA

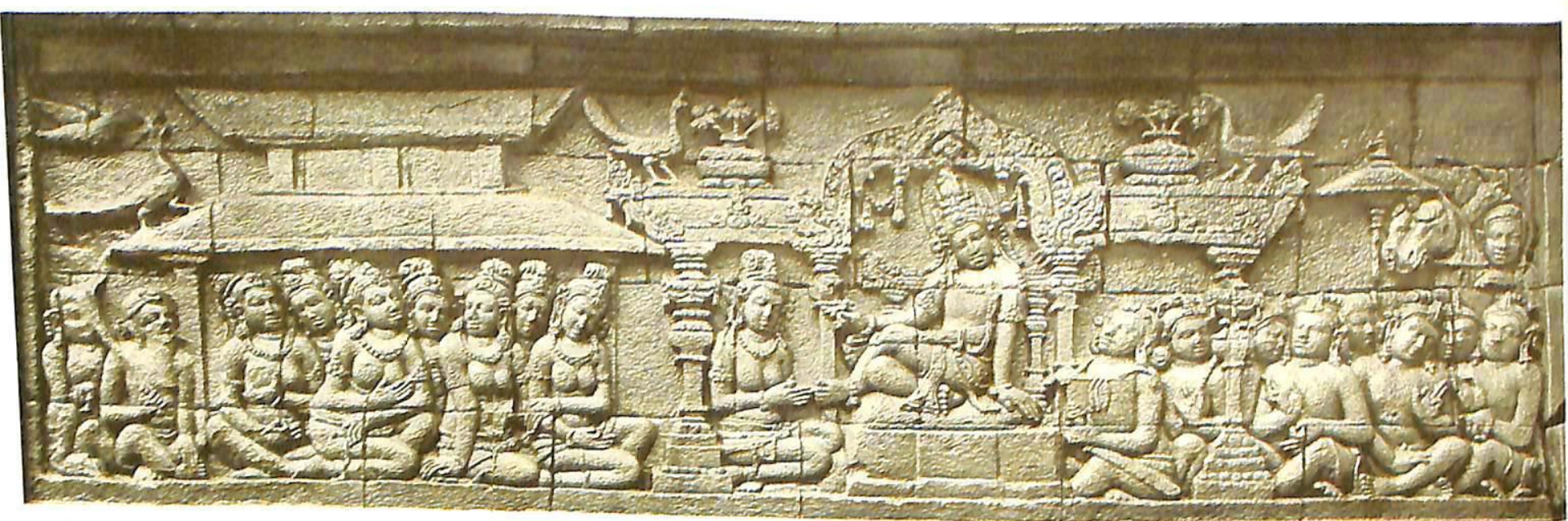

Relief :

Pangeran Sidharta memberikan cincin kepada Dewi Gopa dan memilihnya sebagai isteri.

Lokasi :

Sisi Selatan, Dinding Tingkat I relief rangkaian atas bidang $\mathrm{j}$ 